\title{
LINO NOVÁS CALVO EN EL EJE DE LA REVISTA BOHEMIA
}

\section{Cira Romero}

Instituto de Literatura y Lingǘística

«J. A. Portuondo» (A Habana) 



\section{Toda obra valiosa está hecha bajo el impulso \\ de una pasión, y toda pasión, por muy \\ estrafalaria que parezca, está enmarcada, \\ parte siempre, de la vida.}

\section{Reinaldo Arenas}

Permítanme unas breves palabras introductorias, más que necesarias, obligadas en mi caso, antes de leer el texto elaborado:

Cuando recibí el primer aviso de Ramón Villares, presidente del Consello da Cultura Galega, donde me anunciaba la posible celebración de este congreso y, con posterioridad, la seguridad definitiva, mi primer pensamiento fue: «Al fin Lino Novás Calvo será objeto de un homenaje en su tierra de nacimiento».

Debo reconocer que desde hace más de veinte años, cuando me acerqué por vez primera, no a su obra narrativa, ya antes leída, sino a sus cartas, pensaba sobre todo en el dolor expresado por Lino en esas páginas al presentir que escribía para el vacío, que su obra a nadie interesaría, pues desde aquel entonces el autor de Pedro Blanco, el negrero suponía (o creía suponer) que sus cuentos se habían perdido (o se perderían) en un limbo que no le importaba (o le importaría) a nadie: ni a España (Galicia), donde nació y residió por poco tiempo, ni a Cuba, donde vivió largos años, los más fructíferos de su vida como escritor, y donde su nombre y obra fueron borrados del mapa artístico insular por razones que, eufemísticamente, denomino de carácter extraliterario, hoy casi superadas ${ }^{1}$; y tampoco supuso (o supondría) que finalizaría sus días en los Estados Unidos.

Creo que jamás sospechó que en su lugar de nacimiento se organizaría un encuentro para valorar su obra, como el que en 1975 preparó la Universidad de Syracuse, lugar donde trabajó como profesor de Literatura desde 1967 hasta el momento de su jubilación ${ }^{2}$. Ahora, convocados por un mismo amor intelectual, no viene al caso dilucidar las razones de ese olvido, porque, por encima de los más variados criterios, a lo que sí estamos obligados es a reconocer y a estudiar cada vez

1 El centenario de su nacimiento fue recordado en el Instituto de Literatura y Lingüística mediante una mesa redonda que organicé y en la cual participaron algunos narradores y críticos como Ambrosio Fornet y Alberto Garrandés.

2 Los trabajos presentados para esa ocasión se reunieron en diferentes números de la revista Symposium correspondientes al año 1975. 
más la obra de un escritor clave que fue y es gallego, que fue y es cubano y, aunque no sé si se sintió norteamericano, lo cierto es que hay muchas huellas de estos ámbitos -geográficos, culturales, sentimentales- en su obra de ficción y también en su periodismo.

Mi acercamiento más directo, o mejor, más emocional, a Novás Calvo fue mediante cartas de su autoría, y debo entonces compartir con ustedes, brevemente, cómo se fraguó mi percepción a partir de su lectura. Mi vida laboral, de más de cuarenta años, ha estado vinculada al Instituto de Literatura y Lingüística, cuyo director, José Antonio Portuondo, fue uno de los mejores amigos de Lino durante las décadas del 40 y del 50. Un día entré a su oficina y me dijo: «Salvador Bueno -otro buen amigo de Novás- me acaba de devolver las veintinueve cartas que conservó de Lino. Te las presto y después conversamos». Las leí con verdadera fruición y esas páginas, generalmente mecanografiadas y a veces corregidas con una pluma de tinta negra, me fueron devolviendo a un ser humano sufrido, inseguro a veces, tanto con respecto a su vida personal como a su labor como escritor, complejidades propias, la primera, del ser humano, y la segunda, de todo artista, lo cual comporta, cuando este es exigente consigo mismo, dudas, temores, indecisiones y hasta frustraciones. Cuando devolví esas misivas a quien con tanto esmero las había guardado, charlamos largamente acerca de su obra narrativa, que Portuondo fue uno de los primeros en valorar en un trabajo publicado en $1943^{3}$, pero también evocó en esa conversación los frecuentes encuentros informales que sostenían y el trabajo compartido, a mediados de la década del 30, en un espacio radiofónico de carácter cultural ${ }^{4}$, y cómo Lino, mientras esperaba su turno para enfrentar el micrófono, dibujaba constantemente, en pequeños papeles, su autorretrato, algunos

3 «Tarjetero: Cuba literaria (1942)», Revista Bimestre Cubana, La Habana, segundo semestre, 1943, 275-281. Pero quizás el más relevante que publicó sobre este autor fue «Lino Novás Calvo y el cuento hispanoamericano", Cuadernos Americanos, México, septiembre-octubre, 1947, 245-263, incluido posteriormente en El heroismo intelectual (México, Tezontle, 1955, 41-60) y en Estudios de literatura cubana (La Habana, Letras Cubanas, 2011, 163-183).

4 Se trató del programa «Hora Cubana de Cultura Popular», trasmitido por la emisora CMCY, que salió al aire el primer domingo de enero de 1936. La finalidad de este espacio era «difundir ampliamente la cultura en los medios todos de nuestro pueblo, especialmente en el campo dormido y en las pequeñas ciudades del interior, que, en doloroso contraste con la capital fastuosa, vegetan miserablemente sumidos muchas veces en la más espantosa incultura. La HORA CUBANA DE CULTURA POPULAR, sin deberse a partido alguno ni sujetarse a criterio de facción, solo quiere hacer labor cubana, creación de un acento cubano, matiz que nos defina y precise en el concierto universal de la cultura contemporánea». 
conservados por Portuondo en su archivo privado, hoy atesorado en la mencionada institución que lleva su nombre.

Varias de esas cartas, y otras remitidas por Lino a su gran amigo José Antonio Fernández de Castro, fue lo primero que publiqué sobre Lino a finales del siglo Xx. Después vinieron varios libros con recopilaciones y selecciones de su obra cuentística y parte de su periodismo ${ }^{5}$ y, por supuesto, su conmovedor epistolario, conformado con las cartas que de él se conservan en varios fondos personales de la institución donde laboro, más artículos, conferencias, etc. Pero subrayo que otros compatriotas en Cuba y en el exterior, como Carlos Espinosa, que le dedicó su tesis doctoral, entre otros valiosos aportes para el conocimiento de su labor, José Manuel Fernández Pequeño y Emilio García Montiel fueron los pioneros en la labor de reinstalar su obra, a la que se sumaron luego, con variados aportes, Guillermo Cabrera Infante, Lisandro Otero, Ambrosio Fornet, Jesús Díaz, Abilio Estévez, Leonardo Padura, Alberto Garrandés, Aymeé González Bolaños y algunos más, junto a españoles como Jesús Gómez de Tejada, quien me ha sorprendido gratamente con dos libros iluminadores, uno en cuanto cronista y otro dedicado a su única novela ${ }^{6}$, y antes los norteamericanos Lorraine Elena Roses y Raymond David Souza publicaron sendos libros sobre el autor ${ }^{7}$. Asimismo, el ensayista y traductor francés Jean Pierre Paute, además de trasladar a esta lengua en el 2012 su «biografía novelada» Pedro Blanco, también le ha dedicado estudios independientes

5 Los libros que he preparado sobre su obra son Angusola y los cuchillos (Santiago de Cuba, Editorial Oriente, 2003), compilación de cuentos que no recogió en libros; El comisario ciego y otros relatos (Sevilla, Editorial Renacimiento, 2003), que reúne una selección de sus cuentos; Órbita de Lino Novás Calvo (La Habana, Ediciones Unión, 2008), para el cual escogí poemas, cuentos, un fragmento de su novela Pedro Blanco, el negrero, su obra de teatro El ahogao, artículos literarios y periodísticos, ensayos y reseñas sobre libros. En el mismo año apareció por Ediciones La Memoria, del Centro Pablo de la Torriente Brau, Laberinto de fuego, que contiene su epistolario, conformado a partir de sus cartas atesoradas en los archivos personales de escritores cubanos que se guardan en el Instituto de Literatura y Lingüística. En Fragmentos de interior. Lino Novás Calvo: su voz entre otras voces (Santiago de Cuba, Editorial Oriente, 2010), engarcé entrevistas, fragmentos de cartas, cuentos, novela y artículos de su autoría, junto a trabajos dedicados a él, mediante un montaje donde intento desentrañar su vida y su obra. En 2013 la Editorial Renacimiento publicó, bajo el título España estremecida, el volumen que preparé con sus trabajos periodísticos para la revista Orbe.

6 Me refiero a El Negrero de Lino Novás Calvo y la biografia moderna, Sevilla, Universidad de Sevilla, 2013, y Lino Novás Calvo. Vidas extraordinarias. Crónicas biográficas y autobiográficas (1933-1939). Selección, edición y estudio introductorio de Jesús Gómez de Tejada. Madrid, Editorial Verbum, 2014.

7 El libro de Souza, Lino Novás Calvo, editado en Boston por Twayne, data de 1981. El de Roses, Voices of the Stroryteller: Cuba's Lino Novás Calvo, publicado en New York por Greeenwood, de 1986. 
y ahora traduce sus cuentos. Me quedan otros muchos por citar, pero basta con lo expresado para subrayar que, en la actualidad, la obra de Lino Novás Calvo goza de una preeminencia total en el mundo académico, espacio donde quedan mejor asentadas las creaciones de los escritores. Pero aún queda mucho por decir sobre él e, incluso, publicar de él.

Si este reconocimiento crece por días, también comienza a apreciarse que su obra narrativa constituye un punto de giro en la prosa hispanoamericana contemporánea y es antecedente, quizás impensado, del llamado boom literario latinoamericano que irrumpió a comienzos de la década del 60 del siglo pasado a través de voces tan poderosas como las de Gabriel García Márquez, Mario Vargas Llosa y Carlos Fuentes. Si estos y otros autores no se sienten herederos de Lino Novás Calvo por desconocimiento involuntario, es tiempo de apreciar que su obra narrativa constituye raíces legítimas de ese movimiento. Los cuentos que el gallego-cubano escribía y publicaba desde los años treinta -tras cumplir con extenuantes jornadas periodísticas y de traducción- ostentan hoy el sello invaluable de un arte particular de decir y como siempre lo repito: sin miedo a las palabras. Sus punzantes y poderosas narraciones, envueltas en el halo maravilloso y mágico de las historias contadas, forman parte de lo mejor de la tradición literaria latinoamericana del siglo $x x$; $y$, como de manera invariable me recuerda un colega que bien conoce su obra, él integra, sin dudas, la escuadra que compone la división de los "pesos completos» de la narrativa cubana y del resto del continente, y, añado yo, del periodismo, tema escogido para desarrollar a continuación, ceñido al de la revista Bohemia, aunque precedido de breves pero necesarios antecedentes.

\section{PRELUDIOS, ESPLENDORES Y CODAS DE UN HOMBRE APASIONADO POR LA LETRA IMPRESA}

A Lino Novás Calvo se le atravesaron en el camino las lecturas y los libros, para bien, cuando después de instalado en Cuba como un emigrante más, y mientras conocía las vicisitudes en la ciudad, el campo y el mar -mesero, bodeguero, taxista, mandadero, cortador de caña, vendedor de joyas de falso oro, un intento fallido de boxeador, carbonero, trabajador de los muelles en Nueva York y hasta, quizás sin saber con certeza lo que ello significaba, traficante 
de ron durante la Ley Seca dictada por el gobierno norteamericano ${ }^{8}$-, comenzó lecturas desordenadas acompañadas de cuartillas en las que esbozaba, al menos, el barrunto de una idea literaria. Tuvo la suerte de que, mientras trasladaba a un cliente en su «fotingo» de alquiler, este fuera Francisco Ichaso, entonces uno de los editores de la Revista de Avance (1928-1930), principal órgano de la vanguardia literaria cubana. Entablada la conversación, el ensayista apreció las inquietudes literarias y las buenas pero dispersas lecturas acumuladas por el joven conductor. Lo invitó a colaborar en dicha publicación, que apenas había dado a conocer su primer número en marzo de 1928. En el correspondiente al mes siguiente, y firmado por Lino María de Calvo, apareció «El camarada», como parte de la sección «Los poetas inéditos». Con posterioridad siguió participando en esas páginas con composiciones en igual género; pequeños ensayos como el dedicado a León Tolstoi; cuentos; una breve pieza de teatro, El ahogao, de corte vanguardista; más lo que, a mi juicio, estimo fundamental: su labor como crítico de libros para la sección «Letras», donde publicó más de treinta ceñidos comentarios dedicados a textos versados sobre los más diversos temas y géneros 9 . Una labor similar, y paralela por un momento, a la desarrollada en Avance fue la llevada a cabo para la Revista de La Habana (1930) a través de la sección "Libros importantes del mes», donde comentó muchos de los que llegaban a la Librería Minerva, su lugar de trabajo por entonces, establecimiento muy unido a esa efímera pero importante publicación, y donde trabó amistad con otros intelectuales que después serían clave en su vida, como José María Chacón y Calvo. A la vez aparecieron cuentos suyos en dos revistas: en una muy modesta titulada $Z$, de filiación vanguardista ${ }^{10}$, y en Social, de

8 Para un conocimiento pleno de estas actividades véase «Un emigrante en la isla de Cuba. La ciudad, el campo y el mar", crónica en ocho partes, publicadas en el periódico madrileño $L a$ Voz, en números correspondientes a agosto de 1934. Fueron recogidos por Jesús Gómez de Tejada en Lino Novás Calvo. Vidas extraordinarias. Crónicas biográficas y autobiográficas (1933-1939). Selección, edición y estudio introductorio de Jesús Gómez de Tejada. Madrid, Editorial Verbum, 2014, 219-283.

9 Gracias a estas notas críticas, Jesús Gómez de Tejada pudo reconstruir los juicios de Novás Calvo acerca del género biográfico, el preferido al reseñar libros para la mencionada sección de la Revista de Avance. Desde tales perspectivas escribió su novela del año 1933 Pedro Blanco, el negrero. Véase al respecto, del mencionado estudioso, El negrero de Lino Novás Calvo y la biografía moderna, Sevilla, Universidad de Sevilla, 2014.

${ }^{10}$ El primer cuento publicado por este autor, mientras no se demuestre lo contrario, es el titulado «La furnia», aparecido el 15 de marzo de 1929 en esta revista. 
verdadero lujo en diseño e impresión, iniciada en 1916. También tuvo una esporádica aparición en el Diario de la Marina, periódico de larga tradición en Cuba y portavoz de los intereses españoles; y poco después en el semanario gráfico Orbe, fundado en marzo de 1931, adscrito a la empresa editorial que regenteaba el mencionado Diario de la Marina. En Orbe ocurrió su plena iniciación como periodista con dos crónicas excepcionales para un principiante: "Quemando gasolina: confesiones de un botero» (29 de mayo) y «iArrea mula! Confesiones de un carrero» (19 de junio).

La jefatura de redacción de Orbe, desde su fundación, estuvo en manos del citado José Antonio Fernández de Castro, figura clave de la cultura cubana en los años 20 y 30, y gracias a él Lino fue nombrado su corresponsal en Madrid, función desempeñada entre julio de 1931 y mayo de 1933, momento en que los propietarios del periódico emprendieron cambios sustanciales que condujeron al cese del hebdomadario ${ }^{11}$.

Imposibilitado de subsistir con el pago de esos trabajos -fundamentalmente reportajes, crónicas, entrevistas-, se vinculó a otras publicaciones españolas como Revista de Occidente, Los Cuatro Vientos, La Voz, Diario de Madrid, Mundo Gráfico, Frente Rojo, Ayuda y Mundo Obrero, estas tres últimas de filiación republicana, posición a la que se adhirió Novás Calvo, como otros muchos intelectuales del momento. También ejerció como traductor del inglés al español de numerosas obras, desde las novelas Canguro y Contrapunto, de D. H. Lawrence y William Faulkner, respectivamente, hasta textos que, como él mismo expresó en alguna de sus cartas, ni siquiera su nombre figuró en los créditos del libro. Tradujo hasta de una jerga del inglés hablado en Australia, el cockney. «iFigúrate qué trabajo!» ${ }^{12}$, le comenta a Fernández de Castro en una epístola de finales de $1932^{13}$.

A finales de la guerra civil española, tras una larga odisea para marcharse del país, pudo trasponer los ásperos Pirineos y llegar a la capital francesa. Después de

\footnotetext{
${ }^{11}$ La transformación ocurrida consistió en ofrecer en el citado periódico, Diario de la Marina, una sección que titularon «Diario Gráfico», con cuatro páginas eminentemente visuales. "Creemos que de ese modo -advertían en el número del 28 de marzo de 1933- quedará ampliamente compensada la supresión de la revista Orbe». Reapareció en 1941 y se extendió hasta, aproximadamente, marzo del año siguiente. No aparecen colaboraciones de Novás en esta segunda etapa.

12 Jerga del inglés hablada en esa isla-continente.

${ }^{13}$ Laberinto de fuego. Epistolario de Lino Novás Calvo, ed. cit., p. 57.
} 
solucionar no pocos escollos de variada índole, entre ellos el dinero del pasaje para regresar a Cuba, sufragado por Chacón y Calvo, logró, por fin, avistar el litoral habanero. Lino Novás Calvo traía, junto a su maltrecho equipaje, notables credenciales como narrador, periodista y traductor. Era todo un escritor que, como otros muchos, se multiplicó en iguales ejercicios creativos.

Con tal aval fue admitido, como trabajador fijo, en el periódico Noticias de Hoy, fundado en $1938^{14}$, que era por entonces, de modo encubierto, órgano informativo del Partido Comunista, devenido poco después en Unión Revolucionaria Comunista y más tarde, en 1943, Partido Socialista Popular ${ }^{15}$. Allí inició Novás, en el mes de abril de 1939, la columna «Una hora del mundo», donde publicó, aproximadamente, ciento treinta y siete trabajos de corte periodístico variado $^{16}$, nunca recopilados, en los cuales dejó plasmadas, principalmente, sus vivencias sobre la guerra civil española, conflicto bélico que, como él mismo reconoció en más de una ocasión, destrozó sus nervios.

La firma, el 23 de agosto de 1939, del acuerdo germano-soviético de no agresión, conocido como tratado Ribbentrop-Molotov, causó desazón en Novás Calvo, y en algunas de sus colaboraciones para dicha columna dejó traslucir su inconformidad con tal alianza, actitud que, supongo, disgustó a la dirigencia

${ }_{14}$ De ese periódico era jefe de redacción su coterráneo Carlos Montenegro, nacido en la aldea de A Pobra do Caramiñal, A Coruña, en 1900. Se radicó en La Habana definitivamente tras una vida azarosa que incluyó pasar casi catorce años en presidio (1919-1931) por un delito de homicidio. Se vinculó a este periódico desde el mismo año de su fundación, pero previamente participó en la guerra civil española al lado de las fuerzas republicanas. En 1943, por problemas internos con los máximos dirigentes de dicho partido, se alejó de su cargo en el periódico. En 1938 publicó una de las novelas más estremecedoras de la literatura cubana, Hombres sin mujer, que inaugura en las letras hispanoamericanas el complejo tema de la homosexualidad en las prisiones. Fue comentada por Novás Calvo en el periódico El Mundo (2 de mayo de 1939), quien mucho antes también había reseñado su libro El renuevo y otros cuentos (Suplemento Literario del Diario de la Marina, 24 de marzo, 1929). Actualmente, la citada novela, que en su momento tuvo enorme repercusión, alcanza nueve ediciones: la última, en Cuba, en 2013 y ha vuelto a ser objeto de numerosos estudios. Véase al respecto, solo en libros dedicados a este autor, de Enrique J. Pujals, $\mathrm{La}$ obra narrativa de Carlos Montenegro (Miami, Ediciones Universal, 1980) y Vida y memorias de Carlos Montenegro (Miami, Ediciones Universal, 1988); y de Caridade Fernández Tamayo, Hombres sin mujer y mujeres sin hombre (La Habana, Editorial Letras Cubanas, 1981). Emigró de Cuba en 1959 y falleció en Miami en 1981.

15 Aún estando en España Lino había remitido algunas colaboraciones para este periódico.

16 Esta cifra y otras que ofrezco a lo largo del trabajo las he tomado de la Bibliografía de Lino Novás Calvo (2007) elaborada por Carlos Espinosa Domínguez. En búsquedas posteriores he podido sumar otros trabajos, así como rectificar algunas fechas allí asentadas. 
del diario. Si bien sus colaboraciones se mantuvieron estables hasta mediados de 1940, no me quedan dudas acerca de que desde aquella época comenzó su distanciamiento de posiciones políticas de izquierda. En una carta muy posterior dirigida a José Antonio Portuondo le confiesa: «Aunque te escribo en rojo [o sea, agrego yo, escribía con una cinta mecanográfica de ese color], ya yo no soy rojo -ni de ningún otro color, hasta ver si se inventa un color nuevo. Todos los demás están siguatos» ${ }^{17}$. Esta escéptica posición no le impidió sentirse ajeno a la situación cubana desde una postura que enuncia en otra carta: «Yo creo que quien quiera que lo sustente, Cuba necesita un nacionalismo» ${ }^{18}$, y en líneas anteriores expresó: «estoy con los pobres, los chiquitos, los preteridos, los que sufren ${ }^{19}$.

Tras su salida de Noticias de Hoy se vinculó a la revista Ultra. Cultura Contemporánea, fundada en 1936 por Fernando Ortiz bajo los auspicios de la Institución Hispanocubana de Cultura, pero su labor allí, dado el carácter de ese órgano, fue solo como traductor, siempre bajo anonimato, y esporádico director en ausencia del titular, pero sin que su nombre figurara en tal desempeño. En abril de 1945 se retiró de esta publicación por desavenencias con el destacado etnólogo cubano ${ }^{20}$. En ese año, según afirma en una carta a Portuondo: «Mi trabajo está en Bohemia y, marginalmente, dos artículos semanales en Información» ${ }^{21}$. Estos últimos, tampoco recopilados, suman alrededor de noventa y tres, y ofrecen una variada gama de temas, desde asuntos puramente literarios («Hammet y Caín», «El lenguaje en la novela» $\mathrm{y}$ «Un error de Alfonso Reyes» pudieran ser los mejores ejemplos), hasta títulos como "Hogar y vida pública», «Una América sin patitos feos», que le valió el Premio Periodístico Enrique José Varona de ese año, o «Cambios en Buenos Aires».

En cuanto a su relación con Bohemia, quiero adelantar que no siempre fue amable. Me apoyo de nuevo en sus propias palabras, estas de 1948:

Bohemia es algo raro. No sabe uno jamás a qué atenerse. Yo no hago más que llevar mis traducciones y recoger las que me dan. No veo nunca al director. Él es lo más ininteligible

17 Carta a José Antonio Portuondo del 27 de diciembre de 1946, en Laberinto de fuego..., ed. cit., p. 115.

18 Ídem, p. 110.

19 Ídem, p. 110.

20 Véase la carta a José Antonio Portuondo de fecha 9 de abril de 1945, en ed. cit., p. 108.

${ }^{21}$ Ed. cit., p. 108. 
que existe [...]. Por otro lado, las intrigas dentro de la revista son repulsivas [...]. Tengo que aguantarme, prendido con alfileres, sin que sepa cuándo voy a quedarme fuera, pues están publicando traducciones de otros [...] y dejan las mías, siendo más selectas ${ }^{22}$.

\section{CREDENCIALES EN LA REVISTA BOHEMIA}

Sucintamente, resumo el carácter de esta revista desde su creación en 1910: semanal, informativa, profusamente ilustrada a través de las más variadas técnicas, pero con predominio de la fotográfica. Se autocalificaba, con juicio nada exagerado, como «una enciclopedia imprescindible en toda casa en que los habitantes se precien de cultos y amantes del saber», faena bien cumplida a lo largo de los años, pues atendieron en sus páginas los más variados asuntos, desde los de actualidad, incluidos los políticos nacionales e internacionales, pasando por temas literarios (publicación de cuentos principalmente), deportivos, científicos, agrícolas, culinarios, crónica roja, novedades de la moda y un etcétera interminable. Las firmas más prominentes del periodismo cubano y también las polémicas más fuertes en diversas esferas, incluidas las literarias y, sobre todo, las políticas, acompañaron sus páginas, donde también escribieron reconocidos colaboradores extranjeros. Fue una revista excepcional, y aunque en la actualidad sigue publicándose, ahora de manera quincenal, es un reflejo infiel, por no decir lamentable, de lo que fue. Estuvo dirigida desde su fundación por Miguel Ángel Quevedo, sustituido en 1926 por su hijo, Miguel Ángel Quevedo de la Lastra, quien la condujo hasta mediados de 1959.

Bohemia estuvo asociada intrínsecamente a la vida y a la historia de Cuba. Cada viernes llegaba a gran parte de los hogares cubanos, y se convirtió en una verdadera necesidad para aquellos que querían sentirse bien informados y conocer hasta de los comentarios y comidillas que se manejaban en el Palacio Presidencial, como ha subrayado un cronista. La tirada alcanzaba casi medio millón de ejemplares y se distribuía en México, Caracas y Buenos Aires. Un buen número se vendía en los Estados Unidos. Sorteó con sabiduría períodos de censuras de

\footnotetext{
22 Ed. cit., p. 134.
} 
los gobiernos dictatoriales de Gerardo Machado y Fulgencio Batista, y era reconocida como un espacio de plena democracia donde contendían las más diversas posturas ideológicas. A pocos días del triunfo de la Revolución, Fidel Castro le envió este mensaje a su director: «A la revista Bohemia mi primer saludo después de la victoria porque fue nuestro más firme baluarte. Espero que nos ayude a la paz como nos ayudó en estos largos años de lucha». Seis meses después Quevedo salió al exilio y creó, primero en Nueva York y después en Caracas, Bohemia Libre. Novás, se marchó de Cuba en agosto de 1960 -se había asilado, tres meses antes, en la embajada de Colombia en La Habana- y volvió a vincularse a la revista hasta alrededor de 1963. En esta nueva etapa la publicación no alcanzó el esplendor de la precedente.

La labor de Lino Novás Calvo en Bohemia la propongo desde la perspectiva de una triangulación, único modo, a mi juicio, de apreciar el carácter y la relevancia alcanzados: como cuentista, como periodista y como traductor, aspectos mancomunados en sus trabajos hasta constituir una especie de "código maestro» ${ }^{23}$ como expresión totalizadora de su credo artístico-literario. Aunque, por razones obvias, no puedo detenerme como quisiera en cada una de estas facetas, deseo, primero, que sean las cifras las que hablen por sí mismas, y después atenderé a la calidad y al carácter de sus trabajos para ese semanario. Mostraré datos desde el año 1941 hasta $1953^{24}$, pues en enero de 1954 Lino fue nombrado jefe de información de la revista, investidura que, si bien lo condujo a un vínculo de mayor responsabilidad y de una siempre ansiada seguridad económica, implicó una merma considerable como colaborador activo en sus páginas.

Aquí se impone una breve pero necesaria digresión que explique la fortaleza adquirida por Bohemia desde diciembre del año 1953, cuando su empresa editora realizó tres grandes inversiones: compró dos revistas, Carteles y Vanidades, y la editorial Artes Gráficas S.A., en lo que constituyó, en aquel momento, la mayor operación de su género realizada en Cuba. Se creó una entidad llamada Publicaciones Unidas S.A., cuyos intereses se consolidaron en manos de Miguel

${ }^{23}$ La expresión pertenece a Roberto González Echevarría, utilizada en su trabajo «Sócrates yerbero: los negros y la historia», en Lecturas y relecturas. Estudios sobre literatura y cultura, Santa Clara (Cuba), Editorial Capiro, 2013, 164.

${ }^{24}$ Utilizo como fuente básica de información la citada Bibliografía de Lino Novás Calvo (2007) elaborada por Carlos Espinosa Domínguez. 
Ángel Quevedo de la Lastra y su hermana Rosa Margarita, únicos propietarios de la empresa recién fundada. En estas circunstancias, Herminia del Portal, esposa de Lino Novás Calvo desde 1940, quien acumulaba experiencia en el medio periodístico, además de ser destacada poetisa -su libro Agua de paz (1928) había atraído el interés de la crítica-, fue nombrada directora de Vanidades, mientras el asturiano Antonio Ortega, radicado en La Habana desde 1939, periodista de vasta experiencia alcanzada en España, además de narrador, y que fungía como jefe de información de Bohemia, asumió la dirección de Carteles. Se hizo constar en un editorial, donde se informaba de estos cambios, que comenzaba una nueva etapa, calificada de «difícil», mientras que, como parte de la nueva estrategia, en el número del 17 de enero de 1954 apareció el siguiente titular: «Jefe de información de Bohemia» y debajo una foto de Lino en plena labor, acompañada del siguiente pie:

Para desempeñar la jefatura de información de Bohemia [...] ha sido designado Lino Novás Calvo. Baste mencionarle para identificar enseguida al gran escritor cubano de dimensión universal, lograda a través de obras como El Negrero (Madrid, 1933), La luna nona (Buenos Aires, 1942), que mereció el Premio Nacional de Cuentos del Ministerio de Educación; Cayo Canas (Buenos Aires, 1946) y otras muchas de semejante calidad, así como por sus conocidas traducciones de autores como Aldous Huxley, D. H. Lawrence, William Faulkner, Hemingway, etc. Iniciado en 1928, la labor literaria y periodística de L. N. C. [sic] en los últimos 25 años es amplia y fecunda y ha abarcado diversos escenarios: Nueva York, París, Madrid, donde consagró sus valores definitivamente. Cerca de tres lustros como miembro de la redacción de Bohemia, a la que ha aportado su talento, su laboriosidad, su firme condición humana, lo han fundido a esta casa y a su espíritu. Sencillo, cordial, el fraterno compañero cuenta con el afecto de cuantos trabajan en este semanario, que consideran como propios los triunfos de Lino Novás Calvo ${ }^{25}$.

Vuelvo entonces al punto de constatar, en cifras, la presencia de Novás en Bohemia.

25 Bohemia, La Habana, año 46, número 3, enero 17, 1954, p. 62. 


\section{TRABAJOS PERIODÍSTICOS EN DIVERSAS MODALIDADES:}

Diecisiete: el primero, «El siglo de Victoria», el 23 de marzo de $1941^{26}$. El último, «Siminovich el Zorro y sus andanzas por Cuba», el 11 de noviembre de 1951.

\section{Cuentos:}

Catorce: el primero, «Hombre malo», en diciembre de 1941. El último, «Elsa Colina y los tantos millones», el 31 de agosto de $1952^{27}$.

\section{Traducciones:}

Aporto una cifra absolutamente tentativa: alrededor de ciento treinta, aunque pongo en duda que la primera haya sido el cuento "Contracandela", aparecido el 20 de noviembre de $1949^{28}$. La última, «El señor y la señora Barba Azul», de Pierre Mille, el 22 de noviembre de $1953^{29}$.

Dos conclusiones son fáciles de colegir:

1. Lo que más publicó Lino Novás Calvo en Bohemia fueron traducciones.

2. Su presencia en las páginas de la revista mermó a partir de ser nombrado jefe de información en enero de $1954^{30}$.

Dos comentarios suyos en sendas cartas a Portuondo, escritas con posterioridad a su nombramiento, permiten descubrir, en primer término, la tensión que le provocó asumir ese cargo y, en segundo lugar, facilitan la comprensión de por

${ }^{26}$ Este trabajo se insertó en un número extraordinario del semanario en homenaje a Inglaterra, donde colaboraron, como habían prometido en número anterior, «las primeras firmas periodísticas de Cuba».

27 Simultáneamente, aunque nunca con posterioridad a 1953, publicó cuentos en otras revistas cubanas como Grafos, Orígenes, Romance, Trimestre y Mensuario de Arte, Literatura, Historia y Crítica. Asimismo ejerció como profesor de francés de la Escuela Normal de Maestros de La Habana entre 1947 y 1949 , cuando fue destituido por carecer del título oficial que lo respaldara. Fue admitido nuevamente en 1952, pero debió realizar estudios de esa lengua en el Instituto de Idiomas de la Universidad de La Habana. En el último año citado estaba en tercer año.

${ }^{28}$ Recordemos que en una carta a Portuondo del año 1945, antes citada, le comentaba que su trabajo estaba en Bohemia. En otra carta al mismo destinatario, fechada el 24 de abril de 1948, le expresaba: «Yo sigo con mis traducciones para Bohemia. Nada más». Véase Laberinto de fuego, ed. cit., p. 133.

29 Se sabe que realizó muchas más traducciones bajo anonimato, como las pequeñas cápsulas informativas aparecidas en las secciones "Así va la ciencia» y «En pocas palabras", atendidas por él en muchas oportunidades. Localicé, en un número de septiembre de 1957, el texto teatral titulado «Los jugadores», de Nicolás Gogol, en adaptación al francés de Alexander Packer y traducción de esa lengua al español por Lino Novás Calvo. Fue una de las pocas que realizó para Bohemia desde ese idioma.

30 Conchita Fernández, que fuera secretaria de Miguel Ángel Quevedo de la Lastra, ha testimoniado que Novás Calvo, después de ser nombrado jefe de información, se involucró de manera notable en la sección «En Cuba», una de las más importantes de la revista, creada en 1943, que tenía carácter anónimo y cuyo propósito era profundizar, con mirada crítica, en diversos aspectos de la vida nacional. 
qué su presencia real se redujo de manera notable. En la primera carta le expresa: «Por mi parte, estoy desalentado. Todo el mundo quiere escribir para Bohemia, y ocurre alguna de estas cosas: o bien que no saben escribir, que no saben simplemente redactar, o que lo que dicen no tiene emoción ni valor periodístico. Es un verdadero acto de esquizofrenia» ${ }^{31}$. Tal afirmación lleva intrínseca la compleja labor que ahora debía enfrentar: leer, revisar y seleccionar, con alto sentido crítico, los mejores trabajos, e incluso hasta, quizás, corregir algunos, para someterlos al criterio, al parecer bastante exigente, del director de la revista con el fin de que este tomara la decisión definitiva. De la segunda carta se desprende la fuerte carga laboral adquirida después del ascenso: «Contesto brevemente a tu carta. Aunque hoy es domingo, he venido a trabajar -como todos los domingos- y todavía tengo tarea por delante» ${ }^{32}$. Al menos para mí queda claro: se sentía agotado física y mentalmente, sobre todo, para escribir cuentos, en tanto su labor como traductor disminuyó.

Abrevio, también en cifras, su labor en Bohemia Libre:

Trabajos Periodísticos EN DiVERSAS MODALIDADES:

Dieciocho: el primero, «13 mentiras de la propaganda castrista», el 23 de octubre de 1960. El último, «Así era Faulkner», el 22 de julio de 1962.

\section{Cuentos:}

Seis: el primero, «Con un nudo en el corazón», el 24 de diciembre de 1961. El último, «El hombre-araña», el 12 de mayo de 1963.

De los primeros solo conozco los dedicados a Hemingway, cuando el suicido del norteamericano, y su evocación de Faulker al ocurrir su fallecimiento. De los cuentos he podido leer no más de tres. Aunque no dudo de la calidad en ambas manifestaciones, me detendré en los textos aparecidos en la Bohemia habanera, con mayor énfasis en los de carácter periodístico, aunque sin desestimar sus cuentos y traducciones, pues reitero que, a pesar del carácter diverso de cada una de estas zonas de su quehacer, existen nexos muy provechosos entre ellas, cuyos entrecruzamientos pretendo demostrar. Por consiguiente, propongo una interrogante que respondo, desde ahora, afirmativamente, según mis apreciaciones. ¿Podría establecerse una similitud no solo temática, sino estructural, y, en última instan-

\footnotetext{
31 Véase Laberinto de fuego, ed. cit., p. 154.

32 Carta del 30 de octubre de 1954, ed. cit., p. 156.
} 
cia, hasta de propósitos y concepciones artísticas, entre sus cuentos, sus trabajos periodísticos y las traducciones que realizó para Bohemia? Esta tríada, sostengo, resiste la comparación, nada forzada, de líneas armónicas que concuerdan en el plano de los contenidos y de las estructuras, a partir del tratamiento de asuntos que visualizan el lado oscuro de la vida: lo doloroso, lo humano degradante, las situaciones límites, los personajes torcidos, física, emocional y moralmente, los barrios sórdidos, la dureza del medio natural, odios, resentimientos, fecundados y artísticamente logrados gracias a su particular arte de narrar, presentes en sus cuentos, pero también en sus creaciones periodísticas y en sus traducciones.

La sistémica relación que advierto en el mencionado triángulo parte de un tronco común: su arte de decir, lo reitero, sin temor a las palabras, que a él no le importaba que se repitieran, que hubiera una cacofonía, una sintaxis enrevesada u otros posibles «errores», porque, si eran necesarios a sus propósitos, poco le preocupaban. Por encima de estas posibles imperfecciones prevalecía una armazón interna de tal envergadura artística que descartaba, o hasta hacía perdonable, algún posible descuido.

Lino Novás Calvo fue un escritor vital y, por ende, fue un periodista vital, y dejo sentado que su labor en la prensa plana se vincula mayoritariamente con el periodismo afincado en lo literario, no porque atendió temas culturales -aunque a veces lo hizo-, sino por el uso coligado de técnicas literarias y periodísticas dispuestas para comunicar con efectividad y con arte. Es el suyo un caso donde resulta imposible deslindar lo que es periodismo y lo que es literatura, y no porque esté ficcionalizando cuando escribe para la prensa, sino porque tuvo la magia de trocar hechos, experiencias y verdades, de mucha o escasa trascendencia, en esa otra materia que se llama literatura.

La relación entre periodismo y literatura, considerada la rama y el tronco de un mismo árbol, imposibles de vivir separadas, se ofrece en Novás Calvo como una palabra total y al lector le corresponde llenarla de sentido. Por otra parte, resulta un lugar común afirmar que, desde sus orígenes, la literatura alimentó al periodismo. Ambas series discursivas ofrecen coincidencias de notable interés y no puede negarse la influencia de patrones literarios de escritura para la construcción de determinados modelos periodísticos. Asimismo, es irrebatible que la presencia del periodismo en las creaciones literarias del siglo Xx ha sido decisiva. 
En una entrevista que Novás Calvo le concediera en 1956 a Lisandro Otero -en gran parte inédita hasta 1989- expresó: «En el periodismo cabe todo. El papel lo aguanta todo. Y puede ser bueno o malo. Cabe el buen ensayo, el buen artículo y el reportaje, que bien hecho es casi como la literatura» ${ }^{33}$ (cursiva de C.R.).

Según este criterio, salido de su propia voz, el periodismo de Novás Calvo para Bohemia, mostrado en su modalidad de reportajes -menciono por sus valores títulos como «El guajiro: un hombre olvidado» (27 de junio de 1943), «Sentido y presencia de nuestra fiesta de Regla» (10 de octubre de 1944), «La fiesta de la Caridad en La Habana» (16 de septiembre de 1945), «Alfonso Capone, el pandillero» (26 de enero de 1947) y, sobre todo, "Guerra de nervios en Santa Lucía» (15 y 22 de agosto de 1947), que le valió el premio periodístico Eduardo Varela Zequeira-, nos entrega a un escritor dueño de un estilo irreverente, desenvuelto, dinámico, buscando claves que le permitieran irrumpir de modo diferente en una manifestación que, en ese momento, contaba en Cuba con firmas tan reconocidas como las de Jorge Mañach, Eladio Secades, Gastón Baquero y Luis Gómez Wangüemert, entre otras, pero bien distantes del modo suyo, tan personal, de enfrentar esta labor. En medio de una gramática musical a veces nerviosamente hilvanada y sabedor de que, lo cito, «el pueblo no acepta más que lo que le llega al corazón», este profundo observador del entorno vuelve con estos «reportajes literarios», desde una dramaturgia informativa personalísima, sobre temas que de un modo u otro, antes o después, trató o serían tratados en sus cuentos: el campesino desposeído, el hombre en situaciones límites, ambientes de pobreza, sordidez y marginación... También vuelve sobre otros que le entusiasmaron sobremanera y que materializó a través de traducciones: el gangsterismo en los Estados Unidos, el secuestro de niños, asaltos que hicieron historia -estos últimos en una armonía, incluso de visualización y de técnica, casi al unísono ambas, con el llamado cine negro norteamericano, que por los años finales de la década del 40 se iniciaba con rasgos provenientes del expresionismo alemán-, hechos delictivos, hombres duros y mujeres fatales colocados en situaciones límites, esos que tanto interesaron a Novás Calvo ${ }^{34}$.

33 Lisando Otero: «Lino Novás Calvo, recobrado», Unión, La Habana, julio-septiembre, 1989, p. 12.

34 Novás Calvo fue un apasionado del cine. Se entusiasmó porque en Cuba surgiera esta expresión bajo rasgos auténticamente nacionales. En una carta a Portuondo de diciembre de 1947 le dice: "También me hablas de cine. Esa es una de mis pelotas [...]. Por mi parte, quería reunir un grupo de escritores, artistas y músicos y, cooperativamente, hacer entre nosotros una buena película cubana, como muestra y principio». 
De todos modos, volviendo a esos reportajes donde Lino establece «una auténtica conversación con la sociedad $\aleph^{35}$, no puede olvidarse que este orfebre de la expresión tenía a su favor, además de ese don, otro no menos importante: su perfecto dominio del idioma inglés y, por consiguiente, el conocimiento adquirido de primera mano del periodismo norteamericano, porque estaba obligado a traducirlo para Bohemia, e incluso, desde mucho antes, se había vinculado a la narrativa publicada en los Estados Unidos, tan visitada por él como lector y como traductor desde comienzos de la década del 30. Pero en el caso del periodismo se trataba ahora del que se conoce como «nuevo periodismo», iniciado en la gran prensa de los Estados Unidos desde comienzos del siglo xx y en cuyos límites se entrecruzaban la creación literaria y el hecho mismo, aportando la correspondencia artística entre lo objetivo y lo subjetivo y la adopción de puntos de vista, unidos a la metaforización de la vida cotidiana. Sin embargo, a diferencia del practicado en dicha prensa, que abogó más por lo objetivo, él siempre priorizó en sus reportajes la subjetividad del ser humano. Imbuido de la atmósfera de la época y trabajando el periodismo, insisto, con mucha conciencia literaria, sus reportajes muchas veces comenzaban desde la voz de una persona y eso respondía a lo que los periodistas y escritores norteamericanos llaman la you attitude, es decir, "yo siempre me estoy dirigiendo al lector, a ti personalmente, y tengo que cautivarte, captar tu atención». Ese, entre otros muchos recursos, lo practicó Novás Calvo mediante sus reportajes, pero desplazándose siempre por el espacio literario, quizás el único que admitió como auténtico y hasta invulnerable.

Conocedor de los resortes de la profesión periodística, sus «relatos» en función de la prensa se perfilan en continuos ejercicios creadores, pero esa hibridez en la configuración de los valores estéticos lograda por Lino, y con ello de formas literarias en el discurso periodístico, es consecuencia de un devenir histórico cuya génesis también puede hallarse muchos años antes del aludido «nuevo periodismo norteamericano», pues data desde mediados del siglo XIX, cuando en tierras norteamericanas se consolidó la prensa de masas, coincidente en el tiempo con la aparición de la novela realista, buena parte de ella publicada en periódicos.

35 Tomo esta justa apreciación de «Lino Novás Calvo: machacando en su máquina de escribir», en Norge Céspedes Díaz, Lino Novás Calvo, periodista reencontrado, Matanzas, Ediciones Matanzas, 2004, p. 9. 
Desde sus inicios como periodista en 1928, Novás supo que el ejercicio en la prensa y en la literatura discurría mediante códigos diversos pero compatibles, «a través de una relación capaz de generar beneficios insospechados para ambas manifestaciones e insistía en la trascendencia que podían tener los géneros periodísticos, a partir de las dimensiones que cada individuo lograra incorporarle mediante sus capacidades personales, hasta posibilitar incluso determinantes acercamientos a la misma literatura ${ }^{36}$. Remarco entonces, por su importancia, lo que antes leí del propio Lino: «En el periodismo cabe todo. El papel lo aguanta todo. Y puede ser bueno y malo».

Me doy cuenta de que necesito ejemplificar, o mejor, compartir con ustedes, mediante su propia escritura, lo que he intentado expresar acerca de sus reportajes. Me valgo del antes aludido y laureado "Guerra de nervios en Santa Lucía», relacionado con un conflicto de un grupo de campesinos con el poderoso consorcio norteamericano Manatí Sugar Company, en el oriente de Cuba. Voy a citar solo tres momentos de este largo reportaje, donde hubo mucho de investigación por parte del autor. El comienzo:

Bajo el avión la tierra cubana luce como un mapa. El avión ha venido a dar más precisión y amplitud a los mapas. Hoy la tierra se mide, se cuadra, se define, se precisa; no ya por las leguas, sino ya por las pulgadas. Las nuevas escrituras, los papeles, los títulos, corresponden a la tierra. Son como superponibles. Cada nuevo propietario sabe exactamente lo que tiene, dónde lo tiene, con quién colinda.

Eso es ahora. Antes no había cartas, y las medidas eran vagas. Los cabildos daban mercedes circulares que, al tocarse, dejaban entre sí a los realengos, las tierras del rey. Pero nadie sabía, de cierto, dónde empezaban y dónde acababan esos círculos. Los centros (un árbol, un hito) eran confusos y a veces movedizos. Los círculos mismos se superponían, cambiaban de sitio, se estiraban y encogían, según quien los tenía. Con poder e influencia se hacían y prodigaban nuevos títulos (nuevos círculos) que chocaban con otros. Al fin sobre esos papeles, la Isla llegó a tener, por lo menos, doble extensión de la que tiene.

36 Ídem, p. 10. 
A mediados:

El deseo de aprender es lento, como todo en el campo; pero no falta. Los padres quisieran abrir los ojos a sus hijos. Uno nos dice:

- No pretendo que los míos se hagan sabichosos ni que dejen la tierra. Todos mis antepasados vivieron y trabajaron y fueron enterrados en el campo. Pero, al menos, que puedan leer un periódico, conversar y defenderse un poco.

Defenderse es la clave: que sepan leer para que puedan defenderse, si, también a ellos, se les presenta un inspector y les dice: «Oiga, compay, múdese de aquí, que esta tierra no es suya».

\section{El final:}

Nadie ha podido hacer valer este documento. Y los campesinos de Álvaro Reynoso no tienen siquiera documentos. Ellos no tienen nada, salvo sus brazos, sus ranchos y sus esperanzas. Pero ya lo dijo Galiano:

— ¡Dios acude siempre a mayor necesidad!

¡Es la necesidad la que tiene que acudir también el gobierno! ${ }^{37}$

En esos tres segmentos confluyen algunos de los elementos antes esbozados como integrantes de sus rasgos como autor de reportajes periodísticos, y reitero dos de ellos, presentes también en sus cuentos: la ambientación en los estratos menos favorecidos de la sociedad y el modo de expresión asumido. En lo leído apreciamos repetición de palabras desde el inicio, ese «no miedo a ellas»: «Bajo el avión la tierra cubana luce como un mapa. El avión ha venido a dar más precisión y amplitud a los mapas». ¿Por qué no escribió, pregunto, «El avión ha venido a dar más precisión y amplitud a estos»?, o sea, a los mapas, o a las cartas geográficas. Lo hizo así no por descuido, sino porque detrás de esa palabra repetida había una intencionalidad bien marcada, que queda revelada al final del segundo párrafo: "Al fin sobre esos papeles, la Isla llegó a tener, por lo menos, doble extensión de la que tiene». Adviértase que esos «papeles» son los mapas supuestamente

37 «Guerra de nervios en Santa Lucía I», Bohemia, La Habana, 15 de agosto, 1948, pp. 36-39, 75, 80 y 82; ídem, II, La Habana, 22 de agosto de 1948, pp. 20-22, 83-85, 98. 
exactos, pero ahora ya dejaron de serlo pues les otorga un tono absolutamente despectivo: "esos papeles». No es casualidad, sino un modo de reafirmar que esa documentación era falsa. En el resto de los fragmentos vemos el empleo de cubanismos, como compay, denominación amistosa entre campesinos de la zona oriental de Cuba, y que él coloca con la precisión exacta. Emplea un adjetivo en función derivada, sabichoso, utilizado con cierto tono de superioridad. Al final, una conclusión bien explícita: estos campesinos «no tienen nada, salvo sus brazos, sus ranchos y sus esperanzas». Por otra parte, está presente su manera de contar, entre las varias, siempre tan personales, utilizadas ahora de manera magistral. Pero quiero retornar al primer párrafo antes citado, para compararlo con el inicio de uno de sus cuentos. Repito el comienzo del reportaje:

Bajo el avión la tierra cubana luce como un mapa. El avión ha venido a dar más precisión y amplitud a los mapas. Hoy la tierra se mide, se cuadra, se define, se precisa; no ya por las leguas, sino ya por las pulgadas. Las nuevas escrituras, los papeles, los títulos, corresponden a la tierra. Son como superponibles. Cada nuevo propietario sabe exactamente lo que tiene, dónde lo tiene, con quién colinda.

Reproduzco ahora el inicio del que Guillermo Cabrera Infante consideró el mejor cuento de Lino Novás Calvo: «Angusola y los cuchillos», dado a conocer en diciembre de 1947 en las páginas de Bohemia, meses antes del reportaje escogido a manera de ejemplo para ilustrar mis comentarios:

Yo no debiera escribir este cuento. Es un absurdo hablar de nuestros socios cuando, además, lo que a ellos les ha ocurrido pudiera ocurrirle fácilmente a uno mismo. Esto, sin embargo, puede decirse de cualquiera y, al fin y al cabo, la profesión vence a la ética. Este es un cuento sin ética.

¿Por qué Lino escribe «Es un absurdo hablar de nuestros socios cuando, además, lo que a ellos les ha ocurrido pudiera ocurrirle fácilmente a uno mismo», y no «Es un absurdo hablar de nuestros socios cuando, además, lo que a ellos les ha ocurrido pudiera sucederle fácilmente a uno mismo»? O sea, sustituir la forma verbal en infinitivo y enclítica "ocurrirle» por una bastante similar, «sucederle». Sencillamente porque ese era su estilo, sus «maneras de contar», como tituló el 
libro de cuentos publicado en 1970. Repetir palabras, pero de modo tal que no importunaran al lector, ni siquiera al más purista de nuestra lengua, fue un detalle que jamás le preocupó. Pero, además, en este pequeño fragmento de «Angusola...», si lo comparo con el inicial de "Guerra de nervios...», advierto una misma cadencia, una similar colocación de las palabras, una seguridad en la expresión y, sobre todo, una intención de contar que se torna muy explícita en este reportaje, que narra, describe, incita, juzga, pondera, censura, tal como hacía en sus cuentos. Este criterio, motivado desde la comparación, pudiera establecerse entre otros muchos cuentos y reportajes, pero no es ahora el momento. Reitero entonces que Lino Novás Calvo aportó, mediante este género periodístico, informaciones interpretativas y valorativas de hechos determinados, actuales de su momento histórico o actualizado en el sentido de llevar hechos del pasado y relacionarlos con el presente, como hizo en algunos de sus cuentos. Asimismo dispuso del suceso al propio tiempo que lo juzgó, asumiendo así, por momentos, carácter de cronista y dando su versión bajo un sello personalísimo.

Paso entonces a la traducción, que, como expresé antes, fue cuantitativamente el aporte fundamental de Novás Calvo a Bohemia.

No puedo sustraerme a glosar uno de los pocos trabajos suyos, sino el único, donde elaboró una breve pero importante y personal teoría de la traducción, a modo casi de un decálogo. Se titula «Nota sobre traducción» ${ }^{38}$. En sus consideraciones intentó pautar cómo asumirla «fielmente». Dice: «La fidelidad en la traducción puede tener dos movimientos contrapuestos. Uno, para acercar el lector de la traducción al autor del original; otro viceversa», disyuntiva que esclarece por si hubiera alguna confusión: «o el traductor trae la montaña al lector, o bien lleva al lector a la montaña». Y precisa: «o el traductor violenta, por así decir, su propio idioma, para acercar al lector, o bien lleva el lector al decir del autor, o por el contrario violenta el original para acercarlo al modo ordinario de entender del lector». Y, concordando con su amigo José Ortega y Gasset, concluye: «el lector debe ir a la montaña. La misión del traductor, es, pues, en principio, llevar, por su ciencia y por su magia, el lector de la versión, al autor original». Una vez establecido este molde, expresa ciertos reparos, pues es consciente del esquematismo de

38 Fue publicado en septiembre de 1950 en el Mensuario de Literatura, Historia y Crítica, La Habana, septiembre, 1950, pp. 1 y 24. 
lo que ha asumido como esencia del acto de traducir, porque, resumo citándolo puntualmente:

1. «Una palabra no es una pieza de máquina, sino un organismo vivo, que sufre múltiples modificaciones en su evolución, por el tiempo y en el espacio».

2. «Es labor de mucho cuidado y de aguda sensibilidad hallar que la palabra -la original y la de la traducción- se correspondan siquiera aproximadamente, no solo en su valor semántico aparente, aceptado, sino también en sus variables estados de ánimo y salud».

3. «Toda literatura verdaderamente viva lleva tácitamente en sus elementos rítmicos ciertas entonaciones de valor semántico y artístico que los mejores lectores perciben con su "oído interior". El buen traductor no puede tampoco dejar de percibirlo; solo así podrá traducir "todo" lo que traduce; y no solo su forma más obvia y simple».

4. «El acercar el lector de la traducción al autor original debe ser, pues, el primer propósito. [...] Cada autor (particularmente cada autor de creación) tiene su propio "idioma" (no solo su propio estilo) y es ese idioma particular, y no todo ni cualquier parte del idioma original, al que hay que llevar al lector. No hacerlo así es viciar ya de origen ese mandamiento primero a que hemos aludido: fidelidad».

5. «Entenderse íntima y profundamente [con otro idioma] supone el empleo de las mismas claves (y exactamente en la misma forma) que señalan hacia una experiencia común viva y presente, y esas claves no se reducen a la acepción formal de la palabra media [...]. En la traducción, ese objetivo de intimidad del lector con el autor no se logra sino a riesgo de ser mal comprendido».

6. «Reproducir con la máxima fidelidad posible en su idioma, el idioma del autor que traduce, hasta el punto, si posible fuere, en que la línea divisoria entre el pensamiento del original y el de la traducción se borre por completo".

7. El traductor debe «buscar o crear en su propio idioma, las formas y combinaciones capaces de producir notas similares en los lectores para los cuales traduce». 
La síntesis, a partir de sus propias consideraciones, nos conduce a apreciar que Novás Calvo asumió el arte de traducir desde una posición muy comprometida con el texto en sí mismo, y ese acto debió constituir para él una angustia más, muy semejante a cuando se torturaba escribiendo cuentos. No puedo detenerme, como quisiera, en el aspecto que ahora comento -solo subrayar, para entroncarlo con lo expresado acerca del periodismo y lo que expresaré acerca de su cuentística, para demostrar la antes aludida triangulación-, pero al menos deseo dar algunos títulos de las traducciones que hizo para Bohemia, escogidos al azar y exponentes de su empatía con los temas por él preferidos: «Asesinato en Hollywood», «El caso de la víctima de hierro», "Yo he vivido doce años con Hitler», «Los novatos que descubrieron el asesinato perfecto", "Confesiones de un ex presidiario", "Giles de Rais, el hombre más perverso de todos los tiempos», "Historia de un ladrón», "Una lección de criminología», «Muerte en el acantilado», «Invitación al asesinato», "Un revólver bien empolvado», «El asesino cogido por la oreja», «El asesino respetuoso» y me detengo en «Secuestro y muerte de Bobby Greenlease. El más horrendo crimen cometido en los Estados Unidos desde la era del gangsterismo» ${ }^{39}$, que fue, cito, una "Información Especial de nuestro corresponsal Denis Laud», con «versión y arreglo de Lino Novás Calvo». No conozco el original en inglés de esta última traducción, pero sí puedo notar, o al menos intuir, solo basándome en mi experiencia como lectora de su obra, lo que de sí mismo injertó Novás Calvo al hacerla, cuando, por ejemplo, alude a la mansión del acaudalado señor Bobby Greenlease. Leemos: «Su enorme casa colonial, de ladrillos color de miel era el centro y como el corazón de una sociedad que el dinero había hecho fuerte y que el tiempo estaba haciendo distinguida». Ese color de miel aparece en más de uno de sus cuentos, bien atribuido a unos ojos, a la piel de una mujer o al del sol al caer la tarde; y más adelante, al referirse a la hija del magnate, describe su «cuadrado rostro de campesina», que así aparece en su narración «Ojos de oro", cuando alude a uno de sus personajes femeninos. En otro momento, al mencionar a Carl Austin Hall, organizador del secuestro del hijo del millonario, dice al traducir que fue «acumulando delitos y soltando escrúpulos», otro modo de decir muy novasiano; e igual, sobre esta misma persona, cuando expresa que iba «rodando por las tabernas», expresión muy de él, como igualmente cuando alude

39 Bohemia, La Habana, año 45, número 42, octubre 18, 1953, pp. 52-56, 80-82 y 95. 
al propio Carl Austin: «las brujas guiaban sus pasos». Y se refiere a un «pisicorre colorado" propiedad del delincuente, color este último muy utilizado en el lenguaje coloquial cubano. Más adelante, al describir a la cómplice del secuestrador, traduce (o quizás pone de su propia cosecha) que era «amazacotada de cuerpo y rostro» y el pelo, como el pisicorre del secuaz a quien servía, era igualmente, dice Lino, "colorado (natural o teñido)». Hay un momento, y recordemos que se trata de una «versión y arreglo de la traducción», donde se lee:

La escena conforme a nuestros datos, puede haber sido asi (cursiva de C. R.):

Era como una calle abierta hacia ninguna parte. Tenía el dinero, sin marcas, sin trampas. Hubieran podido tener más. Todos los millones de Greennlease hubieran podido ser suyos, y aún el anciano padre se habría sentido feliz y la joven madre hubiera rogado a Dios por su alma si le hubieran devuelto a su Bobby.

Este breve párrafo, sobre todo su oración inicial, «Era como una calle abierta hacia ninguna parte», es, en mi opinión, de la más auténtica cosecha de este autor. Ahí está, sin dudas, su estilo seco, duro, directo, basado ahora en una especie de infinito inasible. Es uno más entre otros recursos literarios propios puestos ahora al servicio de esta libre traducción. Y esos ojos del asesino Carl que «se pegaron unos a otros como tazas de succión» es, para quien conozca sus cuentos, un símil hecho a la medida misma de su arte narrativo. Incluso, porque así, supongo, le pareció que expresaba mucho mejor el sentido de aquella horrorosa historia de crimen, dejó en inglés algunas sencillas oraciones: «My god, you are pretty!», al referirse a una prostituta que le brinda sus favores al homicida. Y en los finales, cuando la compinche del criminal es apresada por la policía, vuelve a referir que "de su antigua personalidad [solo quedaba] el rostro carnoso y el pelo colorado». El recurso del leitmotiv, ahora centrado en el color del pelo y del automóvil, es un rasgo definido de su escritura y, creo, uno de sus aportes para versionar esta pavorosa historia y darle verdadero sabor para acercarla a los lectores.

Por razones de espacio no puedo seguir mencionando los trabajos que tradujo para Bohemia, pero, como se sabe, más de un $90 \%$ fueron tomados casi siempre de publicaciones norteamericanas y se acercan a temas que de un modo $\mathrm{u}$ otro trató en sus cuentos, pero también descubrimos que en otras traducciones se detecta su interés por la ciencia, en particular por los adelantos científicos, 
permanente hasta los días finales de su vida. Tradujo artículos sobre la bomba atómica, la penicilina, los avances en la aviación y acerca del insomnio, sus causas y posible curación.

Pero si de traducciones se trata, sin dudas la más notoria, la más repetida por numerosas editoriales españolas hasta los días actuales y la que tiene, quizás, una historia más rocambolesca fue la que realizó de El viejo y el mar, novela de Ernest Hemingway publicada en 1952 y que le valió el Premio Nobel de Literatura en 1954. En fecha bastante reciente se localizaron en la casa-museo del escritor norteamericano, situada en Finca Vigía, en la periferia de La Habana, cuatro cartas de Lino a este escritor relacionadas con este nuevo desempeño de Lino como traductor ${ }^{40}$. En la primera, fechada el 22 de diciembre de 1952, queda claro que Hemingway puso como condición para publicar esta novela en la edición de Life en español que Lino fuera quien la hiciera, pues este le agradece "por el empeño que usted ha puesto en que sea yo el traductor. Trataré de merecer su confianza». Y más adelante:

[...] caso de que pueda hacerla, voy a necesitar consultar con usted algunos puntos. Primero me gustaría conversar un rato sobre el principio a seguir en la traducción. Luego tendré que consultarle sobre los puntos que encuentre oscuros.

Hubo algunas trabas - de ahí la expresión de Lino «caso de que pueda hacerla»- para publicarla en esa revista norteamericana, impuestas por el Colegio de Periodistas de Cuba, y Hemingway, molesto por la dilatación, aceptó la propuesta de Quevedo de darla a conocer en Bohemia. De inmediato Hemingway pidió que localizaran con urgencia a Novás para que emprendiera la labor y publicarla completa en esta revista ${ }^{41}$, aun cuando perdería una buena suma de dinero, pues el pago de Life en español era muy superior al propuesto por Bohemia. En la segunda carta de Lino a Hemingway, del 28 de septiembre de 1952, le comunica: «Estoy empezando a traducir», y el 12 de diciembre le anuncia: «Ya está la traducción. He trabajado durante las vacaciones [...]. Olvidé de preguntarle una palabra

40 Véase, de mi autoría, el trabajo «Novás Calvo a Hemingway: cartas inéditas sobre El viejo y el mar y otras variaciones sobre el mismo tema», La Gaceta de Cuba, La Habana, número 3, mayo-junio, 2019, 18-20.

41 Esta información la obtengo de una entrevista que el periodista cubano Ciro Bianchi le hizo a Herminia del Portal en 1992 y que publicó bajo el título «Hemingway en Bohemia». 
de la que no estoy muy seguro: sand fleas. ¿Querría decírmela por teléfono, para ganar tiempo? Por lo demás, espero que sea de su agrado. He procurado guardar el sabor original hasta donde lo permite el castellano» ${ }^{42}$. Se sabe que para lograr un trabajo de excelencia Lino contó, además de con la ayuda del propio autor para algunas precisiones, con la de un capitán de cabotaje de origen vasco, amigo del norteamericano. Fue la única traducción al español de El viejo y el mar que contó con la aprobación de su autor y ha sido la más reproducida. En el número de Bohemia del 22 de febrero de 1953 aparece, a toda página, este anuncio:

¡Sensacional! ¡Exclusivo! Bohemia publicará El viejo y el mar, una obra maestra de la literatura americana que podrá usted apreciar por primera vez en español como si la leyera en inglés. ¡Y ES UNA NOVELA CUBANA! por Ernest Hemingway. El más original, el más vigoroso, el más humano de los novelistas americanos de nuestro siglo. Traducción de Lino Novás Calvo, revisada y autorizada por el autor. Una originalísima narración que jamás podrá usted olvidar.

Esta propaganda se repitió en números sucesivos hasta que vio la luz en el correspondiente al 15 de marzo, pero con una tirada independiente a la de la revista. El 30 de ese mes apareció la misma traducción, con ligerísimas modificaciones, en Life en español, pero con el nombre del traductor omitido, estrategia utilizada para no violar la disposición del Colegio de Periodistas de Cuba. Valga decir que con el dinero ganado por la traducción para Life, Lino, siempre gustoso de manejar, se compró un automóvil de segunda mano, algo que le causó mucha gracia a Hemingway, quien donó sus haberes a una causa noble ${ }^{43}$.

No podía extrañar que Lino Novás Calvo pusiera todo su empeño en trasladar El viejo y el mar al español, pues el tema, al que no es necesario referirse por ser harto conocido, estaba en el centro de sus intereses, no ya como traductor, sino como escritor. En el artículo necrológico que Novás le dedicó en Bohemia Libre, aparece un fragmento, a modo de comparación entre ambos, que siempre me ha

42 Para más noticias acerca de estas cartas véase, de mi autoría, el trabajo «Novás Calvo a Hemingway: cartas inéditas sobre El viejo y el mar y otras variaciones sobre el mismo tema», La Gaceta de Cuba, La Habana, número 3, mayo-junio, 2010, 18-20.

$43 \mathrm{El}$ dinero fue empleado en comprar televisores para los niños leprosos recluidos en un hospital habanero donde se atendía esa enfermedad. 
conmovido por su alto grado de sinceridad y hasta de dureza de Lino consigo mismo:

Lo que le llamaba la atención [a Hemingway] era que ni mi tono ni mi figura conjugaban con lo que sabía de mí: que -como él- había sido corresponsal de guerra, que -como él- había escrito cuentos de lucha y muerte, que -como él- había estado en el lugar de los hechos. Esto no rimaba con la persona que tenía delante. No podía haber mayores contrastes: él era grande y fuerte; yo, pequeño y endeble; su voz era recia y dura; la mía débil y blanda; él era brusco y altanero; yo, cauteloso y humilde. Otra paradoja: Hemingway se parecía a su obra; yo no me parecía a la mía ${ }^{44}$.

No puedo concluir sin antes aludir, o mejor, reiterar, mis apreciaciones sobre sus cuentos, porque debo sostener mi tesis acerca de la triangulación entre este género, su periodismo y sus traducciones para Bohemia, el "código maestro" al que aludí antes y que los identificó. Me sirvo de las cifras antes aportadas: de los catorce cuentos localizados en Bohemia entre 1941 y 1952, solo dos colocó en libros: "Hombre malo», en La luna nona y otros cuentos, publicado en 1942, y «La visión de Tamaría», en Cayo Canas, de 1946. De los restantes, cuatro reuní en Angusola y los cuchillos y otros relatos, y ocho aparecieron en 8 narraciones policiales, en 1995.

Si en el género biográfico Novás Calvo fue capaz de ofrecer, como ha hecho notar Jesús Gómez de Tejada en su libro Vidas extraordinarias. Crónicas biográficas $y$ autobiográficas (1933-1936), sus apreciaciones e incluso incipientes teorizaciones sobre el mismo, vertidas en breves reseñas bibliográficas, con el cuento sucedió algo similar, pues, a la altura de 1929, apreciaba que «la liebre de este género es animal de patas muy ligeras y olfato exquisito, a la cual es muy difícil encañonar, hasta por los mismos cazadores de emociones» ${ }^{45}$. Y muchos años más tarde, en una entrevista concedida a Víctor Batista Falla, lo reiteraba, pues, decía Lino, es una manifestación donde:

44 "Adiós a Hemingway", Bohemia Libre, Miami-Caracas, julio 16, 1961, 51.

45 A propósito de un comentario sobre el volumen de cuentos Chinchilla (1929), de Ramón Martín, publicado en la sección «Letras» de Revista de Avance correspondiente a diciembre de 1929, 280. 
[...] uno tiene que contar brevemente y con firmeza una historia. Redondearla [...]. De lo contrario ya no sería cuento [...]. Cada cuento es una manera diferente de narrar. Me ha tocado surgir en una encrucijada literaria, y en todo el tiempo que llevo escribiendo no he hecho más que tantear, en procuración de un estilo que se ajustara a lo que yo quería expresar ${ }^{46}$.

Lino Novás Calvo tuvo la virtud de saber aprovechar los aportes más válidos e imperecederos del criollismo -realismo, paisaje, el hombre mismo, el lenguaje popular- y del expresionismo, en su propósito de desnudar, en el personaje local, la más honda e individual esencia humana y, a la vez, universalizarla, para brindarnos cuentos que son, ante todo, auténticamente cubanos por la fidelidad a la propia circunstancia y universales por su feliz ahondamiento en la común entraña humana. Lo que se impone en ellos, como ocurre con sus reportajes y también con la mayoría de las traducciones realizadas, es lo humano, aunque haya incidencia de otros aspectos. En la conjunción de esas tres creaciones suyas, que de tal califico también sus reportajes y traducciones, concurren, también en el cuento, peripecias apasionantes, alejadas de la fría descripción o la mera exposición, además del hábil manejo del enfoque, de los aspectos más significativos del escenario y de la propia anécdota, que toma y recrea a partir de elementos tomados de la realidad cotidiana, en un proceso vital debatido muchas veces entre la fatalidad y la muerte. El hombre acechado por la angustia y por un destino que, casi siempre, termina aniquilándolo, ese hombre perseguido, acosado en sus más disímiles probabilidades, estructura la mayoría de sus cuentos y, en cuanto configuración totalizadora, está presente en sus reportajes y en sus traducciones.

Reproduzco un fragmento de ¿un reportaje, un cuento, una traducción? Ustedes dirán de qué se trata:

A la una o a las dos [de la tarde] se presentaba la pareja [de soldados] con la orden:

- A ver, Fulano, que nos acompañe al cuartelillo.

El hombre era avisado, venía (del platanal o del monte).

- ¡Vamos, para adelante!

\footnotetext{
46 «¿A dónde va nuestra narrativa?», Exilio. Revista de Humanidades, Nueva York, otoño, 1072, 22.
} 
El hombre seguía. Lo conducían al cuartelillo. De camino, la pareja recogía otros hombres. A veces, eran diez, otras llegaban a veinte. Las distancias son largas, los bohíos están dispersos, y cuando llegaban, finalmente, al cuartelillo, se hacía de noche. Si no había guardias francos, las camas estaban ocupadas, y los detenidos, padres de familia, tenían que dormir en el suelo. Si un par de guardias estaba de licencia, había sus camas. En ellas dormían los más viejos. Los demás, en el suelo.

Se trata de un breve fragmento del antes referido reportaje «Guerra de nervios en Santa Lucía». ¿Pero acaso no pudiera ser también un fragmento de un cuento o una de sus traducciones?

Las páginas de Bohemia significaron para Lino Novás Calvo su grandeza como periodista y lo reafirmaron en su larga trayectoria como cuentista y traductor. La asombrosa capacidad para contar y recrear historias, la posibilidad que tuvo de elevar la tensión dramática en diversas modalidades genéricas y la virtud de hacer más artísticas sus historias reales, así como la destreza para develar sucesos a veces caóticos y asombrar a los lectores por la verosimilitud enunciada en la historia, lo elevan al plano de lo que siempre fue: un creador que huyó de los esquemas rutinarios para darle vida y color a sus textos de cualquier naturaleza. Por otra parte, en algún momento habrá que estudiar, desde la antropología y la etnografía, su obra narrativa, donde se asientan, en cuanto creación literaria, las llamadas ficciones del archivo, que forman parte de la actual narrativa latinoamericana ${ }^{47}$.

Lino Novás Calvo, con la reciedumbre de un estilo único y diverso a la vez, fue un intelectual de la palabra escrita que «habló en prosa» y un periodista definitivo, e hizo de su escritura un acto de entrega no pocas veces dolorosa. Rompió estructuras y se apropió de un modo de decir porque controló el idioma a sus intereses, tuvo disciplina y método para indagar y ajustar todo el material antes de sentarse ante la fría y temida página en blanco, supo ser modesto y nunca se sintió por encima del lector, que siempre lo acompañó en sus intensas aventuras. Fundador del moderno periodismo cubano, trajo un soplo de aire florecido a las páginas siempre inquietantes de Bohemia, revista a la que fue fiel aun cuando hubiera entorpecido, en alguna medida, su labor como narrador.

47 Véase al respecto, de Roberto González Echevarría, su trabajo «La novela como mito y archivo: ruinas de Tlon», en ed. cit., 251-326. 